\title{
Direct correlation between modulus and the crystalline structure in isotactic polypropylene
}

\author{
A. Menyhárd ${ }^{*}$, P. Suba ${ }^{3}$, Zs. Lászlón ${ }^{3}$,H. M. Fekete ${ }^{3}$, Á. O. Mester ${ }^{3}$, Zs. Horváth ${ }^{1}$, Gy. Vörös ${ }^{1}$, \\ J. Varga ${ }^{1}, J$. Móczó $^{2}$ \\ ${ }^{1}$ Laboratory of Plastics and Rubber Technology, Department of Physical Chemistry and Materials Science at Budapest \\ University of Technology and Economics, H-1111 Budapest, Müegyetem rkp. 3., Hungary \\ ${ }^{2}$ Hungarian Academy of Sciences, Chemical Research Centre, Institute of Environmental and Material Chemistry, H-1025 \\ Budapest, Pusztaszeri út 59-67., Hungary \\ ${ }^{3}$ Tisza Chemical Works Ltd., H-3581, P.O. Box 20., Hungary
}

Received 9 October 2014; accepted in revised form 15 December 2014

\begin{abstract}
Mechanical properties and crystalline structure of isotactic polypropylene (iPP) types were studied using polymers, which were polymerized differently in order to obtain diverse molecular architectures. The objective of this work is to describe quantitative correlation between the crystalline structure and the elastic modulus in order to predict structures with expectably advantageous properties. The molecular mass was measured by gel permeation chromatography (GPC) and the regularity of molecular structure was investigated by Fourier transform infrared spectroscopy (FTIR) and stepwise isothermal segregation technique (SIST). The chain regularity of the studied samples is varying in a wide range according to the results of SIST and FTIR measurements. The crystalline structure was characterized by differential scanning calorimetry (DSC) and wide angle X-ray scattering (WAXS). The tensile properties were determined by standardized tensile tests. The results indicate clearly that the increased chain regularity is accompanied by a proportional advancement in crystallinity and consequently proportionally larger stiffness. Moreover, the results of this work were compared to those obtained on other previously produced iPP samples and it can be established that the correlations found during this work are valid generally. An empirical model was developed also, which connects the stiffness to the structural parameters of iPP and makes possible the design and prediction of materials with targeted molecular structure and properties.
\end{abstract}

Keywords: mechanical properties, modeling and simulation, crystalline structure, structure-property correlation, stiffness

\section{t1. Introduction}

iPP is one of the commodity polymers used in large quantity nowadays [1]. Its advantageous price/performance ratio is the key to the success of this polymer. iPP is a crystalline polymer and its properties are determined by its complex crystalline structure [1]. The basic structural units of iPP are the chainfolded fibrillar or lamellar primary crystallites, which can be classified into supermolecular structures with diverse geometry (spherulites, cylindtrites, hedrites, quadrites, etc.) [2-4]. Moreover, iPP has three crys- talline modifications ( $\alpha$-, $\beta$ - and $\gamma$-form) $[2,4-6]$, which influences also its mechanical properties. The monoclinic $\alpha$-modification is the thermodynamically stable form, which is formed during the most frequently applied industrial practices [2].

In the past decades considerable attention was paid to the study of those parameters, which influence the mechanical properties of iPP. A short summary is given about these findings in the followings. Most of the related works describe that the stiffness depends on the crystalline structure developing during the

\footnotetext{
*Corresponding author, e-mail: amenyhard@mail.bme.hu

(c) BME-PT
} 
processing of the product $[1,7-10]$, i.e. the higher the crystallinity the larger the stiffness. The presence of nucleating agents promotes the formation of specific crystalline structures and improves crystallinity, lamella thickness is also larger in the case of effective nucleation [11-14]. Consequently, the stiffness of iPP containing nucleating agent is larger than that of non-nucleated samples [15]. Moreover, some special nucleating agents are selective to the $\beta$-form of iPP $[16,17]$. The $\beta$-modification has lower stiffness and significantly larger impact resistance compared to the $\alpha$-form $[16,18]$. Stern et al. [19] have pointed out that the molecular mass can influence stiffness as well. He found that the increasing molecular mass results in decreased stiffness, because large molecular mass hinders the crystallization process of iPP with due to the kinetic effect. However, we have to note that he has not paid attention to the density and distribution of chain defects in those iPP polymers, which were used during his studies. Gahleitner et al. [20] found similar tendency, but the decreasing stiffness was explained by the different spherulitic structure formed in the polymers with different molecular masses.

The phenomenon that the molecular structure influences the overall crystallinity and consequently mechanical properties is known, however, only few work can be found according to our knowledge, which are linking the molecular architecture to the crystalline structure and to the mechanical properties quantitatively [21-27]. Pukánszky et al. [7] revealed that crystallinity and lamella thickness determines the stiffness of iPP, although the empirical correlation provided by him is applicable only in a limited crystallinity range. The aim of this work is to study the stiffness of iPP samples with diverse molecular architectures and to characterize the effect of molecular architecture (isotacticity and chain regularity) on the crystalline structure and consequently on the tensile properties of iPP. In addition our goal is the development of a theoretical model, which links the crystalline structure directly to the mechanical properties in the entire crystallinity range.

\section{Experimental}

\subsection{Materials and sample preparation}

Five iPP homopolymer grades produced by TVK (Hungary) were used in the experiments. The specification of iPP samples is included in Table 1. In order to produce polymers with significantly differ-
Table 1. The iPP samples used during the recent work

\begin{tabular}{|l|l|l|c|}
\hline \multicolumn{2}{|c|}{ Sample } & \multicolumn{1}{|c|}{ Donor type } & $\begin{array}{c}\text { MFR } \\
\text { [g/10 min] }\end{array}$ \\
\hline iPP1 & ED1 & Propyl-trimethoxy-silane & 2.8 \\
\hline iPP2 & ED1 & Propyl-trimethoxy-silane & 11.0 \\
\hline iPP3 & ED1 & Propyl-trimethoxy-silane & 1.2 \\
\hline iPP4 & ED2 & Cyclohexyl-methyl dimethoxy-silane & 16.0 \\
\hline iPP5 & ED3 & Dicyclopenthyl- dimethoxy-silane & 3.0 \\
\hline
\end{tabular}

ent molecular architectures different external donors (ED) and the same Ziegler-Natta catalyst were applied during polymerization. The polymerization was carried out in a small scale vessel in batch mode at $70^{\circ} \mathrm{C}, 120 \mathrm{~min}$ and $250 \mathrm{~L} / \mathrm{min}$ of stirring. The amount of hydrogen feed was modified, the final MFR is given together with the ED types also in Table 1.

The polymer powders were homogenized with additives (1500 ppm Irganox B 215, 400 ppm glycerol-monostearate, $400 \mathrm{ppm} \mathrm{Ca-stearate} \mathrm{(BASF,}$ Switzerland)) in a Brabender W 50 EHT internal mixer (Brabender $\mathrm{GmbH}$, Germany) at $190^{\circ} \mathrm{C}$, $50 \mathrm{rpm}$ for $10 \mathrm{~min}$ and subsequently were compression molded into $1 \mathrm{~mm}$ thick plates at $190^{\circ} \mathrm{C}$ for 5 min using a Fontijne SRA 100 laboratory compression molding machine (Fontijne, The Netherlands). The platelets were cooled with water in the compression molding machine and the pressure was kept constant during cooling. MFR values were measured after homogenization. DSC, WAXS, SIST, tensile, GPC measurements were carried out on samples cut from these plates. $100 \mu \mathrm{m}$ thick films were compression molded at $190^{\circ} \mathrm{C}$ from the samples for FTIR analysis. Cooling conditions used for films were the same as for the platelets.

\subsection{Experimental techniques}

Melting and crystallization of the polymers was studied by DSC technique using a Perkin Elmer DSC7 apparatus (Perkin Elmer, United States) at a heating and cooling rate of $10^{\circ} \mathrm{C} / \mathrm{min}$. The experiments were carried out on samples with mass of 3$5 \mathrm{mg}$ under $\mathrm{N}_{2}$ atmosphere. The samples were heated up to $220^{\circ} \mathrm{C}$ and held there in order to eliminate the thermal and mechanical prehistory. The crystallinity of the samples was determined based on the melting curve recorded during first heating according to Equation (1):

$X=\frac{D H_{\mathrm{m}}}{\Delta H_{\mathrm{m}}^{0}}$ 
$\Delta H_{\mathrm{m}}$ and $\Delta H_{\mathrm{m}}^{0}$ are the experimentally recorded and equilibrium enthalpy of fusion. The value of $\Delta H_{\mathrm{m}}^{0}$ $(146 \mathrm{~J} / \mathrm{g})$ has been taken from the work of Monasse and Haudin [28]. The SIST experiments were carried out on the same equipment between 160 and $100^{\circ} \mathrm{C}$. After the thermal and mechanical prehistory of the samples had been eliminated at $220^{\circ} \mathrm{C}$ for $5 \mathrm{~min}$ the samples were cooled to $160^{\circ} \mathrm{C}$ at a cooling rate of $80^{\circ} \mathrm{C} / \mathrm{min}$ and held there for 3 hours. Subsequently, the samples were cooled to next crystallization temperature $\left(150^{\circ} \mathrm{C}\right)$ and held there for another 3 hours. Each temperature ramp took 3 hours and the step was $10^{\circ} \mathrm{C}$. After the final crystallization step at $100^{\circ} \mathrm{C}$ was completed the samples were re-heated again and melting curves were recorded. The SIST method assumes; if the polymer is crystallized at high temperature, then only those fractions will be able to crystallize, wherein thick lamellas can develop proportionally to the crystallization temperature. Of course the holding time should be long enough, because the development of crystalline phase at high temperatures is slow. Based on this idea the crystalline structure of the polymer can be fractioned by using appropriate temperature program $[29,30]$. We have to notice here that the accurate experimental condition would be if the sample could be held for endless time at higher temperatures. However, it can be established that if the holding time is longer than 2 hours the loss of fractions with long isotactic sequence is negligible. SIST can be used for characterization of distribution of stereoand regiodefects in iPP similarly to temperature rise elution fractionation (TREF) [31]. According to our earlier observation chain regularity estimated by calorimetry correlates strongly with properties, because they are determined by the crystalline structure [32]. After the samples were crystallized according to the SIST method they were melted at a heating rate of $10^{\circ} \mathrm{C} / \mathrm{min}$. The partial amount of different crystalline fractions can be calculated by separating the melting peaks refer to each crystallization step. From the upper and lower temperature limit of each fraction the characteristic range lamella thickness can be calculated according to Gibbs-Thomson equation (Equation (2)):

$$
T_{\mathrm{m}}=T_{\mathrm{m}}^{0}\left(1-\frac{2 \sigma_{\mathrm{e}}}{\rho_{\mathrm{c}} \Delta H_{\mathrm{m}}^{0} \ell}\right)
$$

where $T_{\mathrm{m}}^{0}$ is the equilibrium melting point, $\sigma_{\mathrm{e}}$ is the free energy of folding surface of the lamella, $\rho_{\mathrm{c}}$ is the crystal density and $\Delta H_{\mathrm{m}}^{0}$ is the equilibrium heat of fusion of iPP. $\ell$ is the lamella thickness. The values of all constants appearing in Equation (2) are included in Table 2. Once the lamella thickness is known, the regular iPP sequence length can be obtained according to Equation (3):

$$
I=3 \frac{\ell}{c}
$$

$I$ is the length of the regular flawless isotactic PP sequence and $c$ is the height of the unit cell of $\alpha$-iPP, which is $6.5 \AA$ according to crystallographic symmetry data [33]. $\ell / c$ has to be multiplied by 3 since iPP chains form 31 helices.

Crystalline structure was studied by WAXS technique as well. Diffractograms were recorded using a Philips PW 1830/PW type equipment (Philips, The Netherlands) with $\mathrm{CuK}_{\alpha}$ radiation at $40 \mathrm{kV}$ and $35 \mathrm{~mA}$ and X Pert PRO MPD type equipment (PANalytical, The Netherlands) with $\mathrm{CuK}_{\alpha}$ radiation at $40 \mathrm{kV}$ and $30 \mathrm{~mA}$. The crystallinity of the samples was determined using the amorphous halo of iPP taken form the work of Boger et al. [35]

The isotacticity of the samples were characterized by FTIR. The spectra were recorded using a Mattson Galaxy 3020 apparatus (Unicam, England) in the wavelength range of 4000 and $400 \mathrm{~cm}^{-1}$. Determination of isotacticity was carried out based on the work of Sundell et al. [36].

Mechanical properties were characterized by tensile testing using an Instron 5566 apparatus (Instron, Germany). Tensile modulus was determined at $0.5 \mathrm{~mm} / \mathrm{min}$ cross head speed and $115 \mathrm{~mm}$ gauge length, while other tensile characteristics were measured at $5 \mathrm{~mm} / \mathrm{min}$ speed.

Molecular mass and its distribution were characterized by gel permeation chromatography (GPC) as well. GPC measurements were carried out using a PL-GPC 210 (Polymer Laboratories Ltd., United Kingdom) equipment according to ISO 16014 standard procedure. The samples were dissolved in 1,2,4-trichloro-benzene (TCB) $(1 \mathrm{mg} / \mathrm{mL})$ at $160^{\circ} \mathrm{C}$

Table 2. All constants, which were used during the calculation of lamella thickness during evaluation of SIST experiments

\begin{tabular}{|l|c|c|}
\hline \multicolumn{1}{|c|}{ Constant } & Value (dimension) & Literature \\
\hline$T_{\mathrm{m}}^{0}$ & $481 \mathrm{~K}$ & {$[2,28]$} \\
\hline$\sigma_{\mathrm{e}}$ & $0.122 \mathrm{~J} / \mathrm{m}^{2}$ & {$[28]$} \\
\hline$\rho_{\mathrm{c}}$ & $936 \mathrm{~kg} / \mathrm{m}^{3}$ & {$[34]$} \\
\hline$\Delta H_{\mathrm{m}}^{0}$ & $146000 \mathrm{~J} / \mathrm{kg}$ & {$[2,28]$} \\
\hline
\end{tabular}


for 2 hours and stabilized by 2,6-di-tert-butyl-4diethylphenol (BHT) $(100 \mathrm{mg} / \mathrm{L})$.

\section{Results and discussion}

\subsection{Molecular architecture}

The molecular mass and polydispersity values of the studied samples are presented in Table 3 and the distribution of molecular mass is represented in Figure 1. The results indicate clearly that IPP3 and iPP5 are so called bimodal polymers, because these grades contain a fraction with larger molecular mass. It appears as a shoulder on the GPC curves and it is reflected on the larger average $M_{\mathrm{w}}$ and $P d$ of iPP3 and iPP5.

The regularity of the polymer chains developed during polymerization using different EDs and hydrogen feed is characterized by the isotacticity and by the regular iPP sequence length. The isotacticity of the polymers was characterized by IR measurements, using the intensity ratio of bands at 998 and $973 \mathrm{~cm}^{-1}$, which ratio is proportional to isotacticity [36]. The results are given in Table 4 indicating that the isotacticity of the samples varies in a wide range. The closer the ratio of $I_{998} / I_{973}$ to 1 the larger the isotacticity, however, we have to mention that the correlation is not linear so the ratio is not equal

Table 3. The molecular mass data of selected materials

\begin{tabular}{|l|c|c|c|}
\hline \multicolumn{1}{|c|}{ Sample } & $\begin{array}{c}\boldsymbol{M}_{\mathbf{w}} \\
{[\mathbf{g} / \mathbf{m o l}]}\end{array}$ & $\begin{array}{c}\boldsymbol{M}_{\mathbf{n}} \\
{[\mathbf{g} / \mathbf{m o l}]}\end{array}$ & $\boldsymbol{P d}$ \\
\hline iPP1 & 231707 & 68882 & 3.4 \\
\hline iPP2 & 207973 & 52559 & 4.0 \\
\hline iPP3 & 420731 & 87589 & 4.8 \\
\hline iPP4 & 222370 & 58993 & 3.8 \\
\hline iPP5 & 311667 & 63971 & 4.9 \\
\hline
\end{tabular}

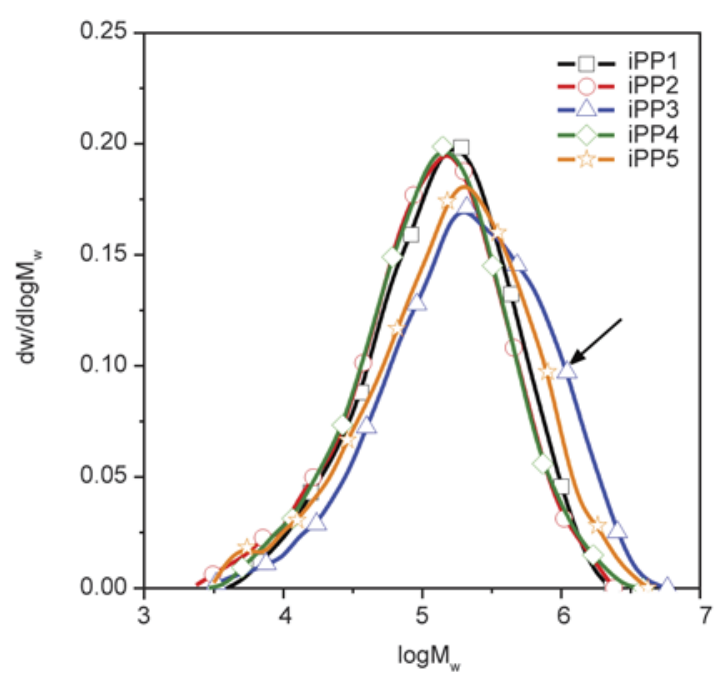

Figure 1. Distribution of molecular mass of the selected polymers
Table 4. The ratio of IR bands at 998 and $973 \mathrm{~cm}^{-1}$

\begin{tabular}{|c|c|}
\hline Sample & $\boldsymbol{I}_{\mathbf{9 9 8}} / \boldsymbol{I}_{\mathbf{9 7 3}}$ \\
\hline iPP1 & 0.81 \\
\hline iPP2 & 0.84 \\
\hline iPP3 & 0.90 \\
\hline iPP4 & 0.93 \\
\hline iPP5 & 0.97 \\
\hline
\end{tabular}

to the isotacticity expressed in percentage. Based on IR results, ED2 and ED3 provide regular isotactic chain structures. The $I_{998} / I_{973}$ value of iPP5 polymerized using ED3 suggests that this polymer has exceptionally regular stereo-structure. The isotacticity of the samples is important, but $I_{998} / I_{973}$ value does not provide any information either about the amount of region-defects or about the distribution of all chain defects.

In order to characterize the distribution of chain defects SIST measurements were carried out. The results of these experiments are demonstrated in Figure 2. It is clear that the different ED systems are resulting in significantly different distribution of chain defects.

According to Figure 2 lots of chain defects are forming during polymerization in the presence of ED1 resulting in relatively low $I$ (iPP1-iPP3). SIST distribution curve of iPP3, which has the largest $M_{\mathrm{w}}$ among iPP1-iPP3, indicate the longest isotactic chain sequence in polymers polymerized using ED1. The chain regularity is significantly larger if ED2 or ED3 were applied and ED3 results in the most regular structure, where the most frequent fraction is longer than 100 regular monomer units. The distri-

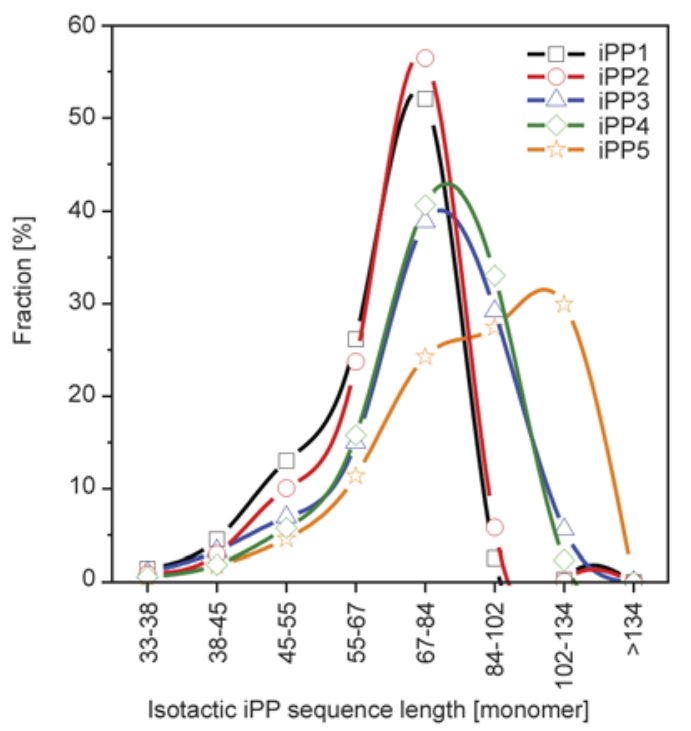

Figure 2. The distribution of length of flawless isotactic iPP sequences 
bution curve reflects the chain regularity nicely, however it cannot be correlated directly to the properties of the polymer, thus the weight average of flawless isotactic sequence length $\left(I_{\mathrm{av}}\right)$ calculated from the distribution curve is used for characterization of chain regularity in the followings. If we know the crystallinity $(X)$ of the sample, which can be calculated from the melting curve after the SIST treatment and $M_{\mathrm{w}}$, the average length of folding chain can be obtained as well. The average number of repeating units $(N)$ can be calculated according to Equation (4):

$N=\frac{M_{\mathrm{w}}}{M_{\mathrm{m}}}$

where $M_{\mathrm{m}}$ is the molecular mass of the repeating units. Consequently, the length of folding chain can be expressed as Equation (5):

$F=\frac{N(1-X)}{\frac{N X}{I_{\mathrm{av}}}}$

The expression of $N(1-X)$ gives the number of repeating units, which are in the amorphous folding sequences and $N X / I_{\text {av }}$ is the number parallel crystalline sequences. In the folded lamella the number of parallel chain sequences are equal to the number of folding of sequences $(F S)$ or $F S+1$. In our case ' +1 ' is negligible, thus $F$ can be calculated according Equation (5). In other words crystallinity can be expressed with the sequence lengths as well (Equation (6)):

$X=\frac{I_{\mathrm{av}}}{I_{\mathrm{av}}+F}$

The correlation between isotacticity and chain regularity and crystallinity is presented in Figure 3. $I_{\mathrm{av}}$ increases with increasing of isotacticity as it was expected, however $F$ decreases much steeper as $I_{\text {av }}$ increases. We have to remark here that $I_{\text {av }}$ is also related to the lamella thickness. It is well discernible that crystallinity increases steeply with the enhancement in chain regularity. The tendencies reported here are very important, because they demonstrate clearly that the crystallinity of the sample can change significantly, while the lamella thickness increases slightly. Therefore, both key parameters - crystallinity and lamella thickness [7] - must be considered during the characterization of change in crystalline structure.

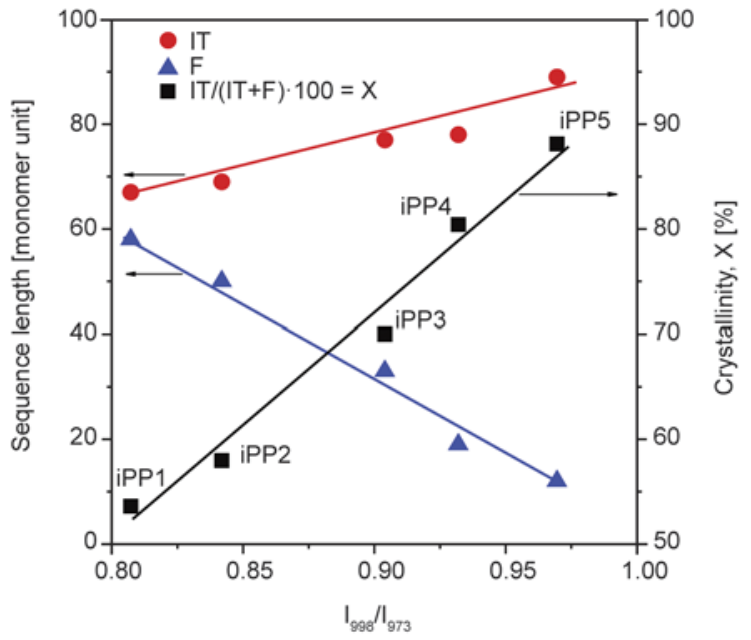

Figure 3. The correlation between sequence length and isotacticity and its effect on crystallinity

\subsection{Crystalline structure of studied materials}

The results of calorimetric experiments are summarized in Table 5. The crystallinity of the samples varies in a wide range. The application of ED1 results in significantly lower crystallinity compared to ED2 and ED3 due to the smaller chain regularity in its presence. The peak temperatures of melting $\left(T_{\mathrm{mp}}\right)$ of iPP1-3 are lower than that of iPP4 and iPP5, representing that thicker lamellas can form in samples with larger chain regularity during dynamic cooling at $10^{\circ} \mathrm{C} / \mathrm{min}$. The effect is pronounced in the case of ED3, which may result in the most regular chain structure.

The crystallinity of the samples was determined from WAXS pattern as well and the results obtained by the two different methods are compared in Figure 4. Although the points presented in Figure 4 scatter, the tendency demonstrates clearly that crystallinity determined by the two experimental tech-

Table 5. Crystallization and melting characteristics of studied samples recorded after elimination of the prehistory of the samples

\begin{tabular}{|l|c|c|c|c|c|}
\hline Sample & $\begin{array}{c}\Delta \boldsymbol{H}_{\mathbf{m}} \\
{[\mathbf{J} / \mathbf{g}]}\end{array}$ & $\begin{array}{c}\boldsymbol{X} \\
{[\%]}\end{array}$ & $\begin{array}{c}\boldsymbol{T}_{\mathbf{m p}} \\
{\left[{ }^{\circ} \mathbf{C}\right]}\end{array}$ & $\begin{array}{c}\boldsymbol{T}_{\mathbf{m}} \\
{\left[{ }^{\circ} \mathbf{C}\right]}\end{array}$ & $\begin{array}{c}\boldsymbol{T}_{\text {cp }} \\
{\left[{ }^{\circ} \mathbf{C}\right]}\end{array}$ \\
\hline iPP1 & 69.2 & 46.7 & 161.8 & 166.5 & 106.1 \\
\hline iPP2 & 80.0 & 54.1 & 162.5 & 167.3 & 107.8 \\
\hline iPP3 & 84.1 & 56.8 & 163.2 & 169.2 & 110.1 \\
\hline iPP4 & 95.6 & 64.6 & 167.5 & 172.3 & 110.8 \\
\hline iPP5 & 100.5 & 67.9 & 168.2 & 172.8 & 112.6 \\
\hline
\end{tabular}

$\Delta H_{\mathrm{m}}$ is the enthalpy of fusion recorded during first heating run $T_{\mathrm{mp}}$ and $T_{\mathrm{m}}$ are the peak and end temperatures of melting respectively recorded during first heating run

$T_{\mathrm{cp}}$ is the peak temperature of crystallization, which was recorded during cooling run 
niques is the same. $X$ was obtained from the first melting trace in DSC measurements, which was recorded before the elimination of thermal and mechanical prehistories in order to represent the complex structure formed during cooling as accurately as possible. Accordingly, $X$ determined from WAXS patterns and DSC traces is characteristic for the crystallinity of compression molded platelets. The equal values of $X$ indicate that the $\Delta H_{\mathrm{m}}^{0}$ determined by Monasse and Haudin is a reliable constant and we are using this constant throughout all of our calculations. We have to remark here that significantly different values of $\Delta H_{\mathrm{m}}^{0}$ can be found in the recent literature (see in the review of Varga [2]), consequently the crystallinity calculated using different $\Delta H_{\mathrm{m}}^{0}$ can be questionable. Figures 3 and 4 prove unambiguously that crystallinity increases steeply with the enhancement of parameters referring chain regularity (isotacticity and regular sequence length). Although, we have to remark here that crystallinity obtained during SIST measurements (Figure 3 ) and that determined by DSC and WAXS on compression molded specimens differ considerably, because of the different crystallization conditions. More perfect crystalline structure with larger $\Delta H_{\mathrm{m}}$ forms during isothermal crystallization in SIST measurement at high temperatures. Data obtained by SIST, WAXS and DSC report similar tendency, thus the effect of chain regularity is the same under dynamic cooling (practical conditions) and isothermal conditions.

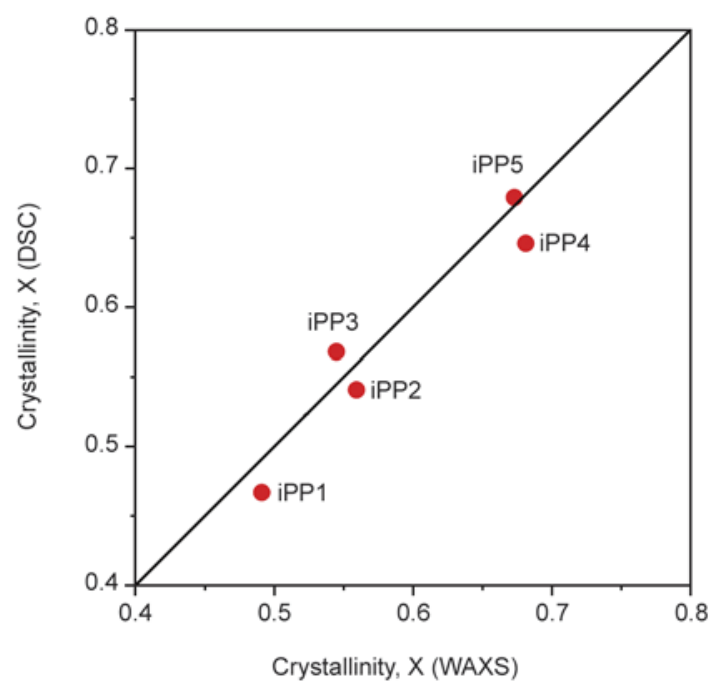

Figure 4. The crystallinity of compression molded platelets determined based on WAXS and DSC measurements
As we mentioned earlier lamella thickness is the second parameter, which should be considered independently, during characterization of crystalline structure. Lamella thickness can be estimated from the melting curves, because each point of the melting curves recorded by DSC can be attributed to a lamella thickness according to the well-known GibbsThomson equation [13]. Romankievicz and Sterzynski [37] reported a possible way for estimation of lamella thickness distribution curve directly from the calorimetric melting curve. Accordingly, the distribution function of lamella thickness can be obtained using Equation (7):

$\frac{1}{M} \cdot \frac{\mathrm{d} M}{\mathrm{~d} \ell}=\frac{1}{M} \cdot \frac{\mathrm{d} E}{\mathrm{~d} T} \cdot \frac{\left(T_{\mathrm{m}}^{0}-T_{\mathrm{m}}\right)^{2} \rho_{\mathrm{c}}}{2 \sigma_{\mathrm{e}} T_{\mathrm{m}}^{0}}$

$T_{\mathrm{m}}$ is the actual melting temperature (each point of the DSC curve), $T_{\mathrm{m}}^{0}$ is the equilibrium temperature of melting, $\sigma_{\mathrm{e}}\left(0.122 \mathrm{~J} / \mathrm{m}^{2}\right)$ is the free energy of the folded surface of a lamella, and $\ell$ is the thickness of the lamella. $M$ is the mass of the crystalline fraction. $\mathrm{d} E$ is the energy needed to melt the crystalline fraction with a mass of $\mathrm{d} M$ in the temperature range of $T+\mathrm{d} T$. The $(1 / M) \cdot(\mathrm{d} E / \mathrm{d} T)$ term of Equation (7) can be measured directly by DSC, because it equals to the recorded heat flow divided by the rate of heating. The second term of the right side of the distribution function (Equation (7)) can be calculated numerically. As a consequence, the lamella distribution curve can be plotted as a function of temperature. The melting curve and the distribution function of iPP 1 are demonstrated in Figure 5 in order to illustrate the method. Figure 5a shows the melting trace and Figure $5 \mathrm{~b}$ is the distribution function.

The distribution function of lamella thickness is difficult to use for the characterization of the material and it is impossible to compare with a modulus data. Thus, the distribution function has to be characterized with one quantity, which can be the thickness at the peak as well as the weight average of lamella thickness. We believe that an entire curve cannot be represented accurately using any of its points, therefore we decided using the weight average of lamella thickness function, which can be deduced according to Equation (8):

$\bar{\ell}=\frac{\int f(\ell) \ell \mathrm{d} \ell}{\int f(\ell) \mathrm{d} \ell}$ 

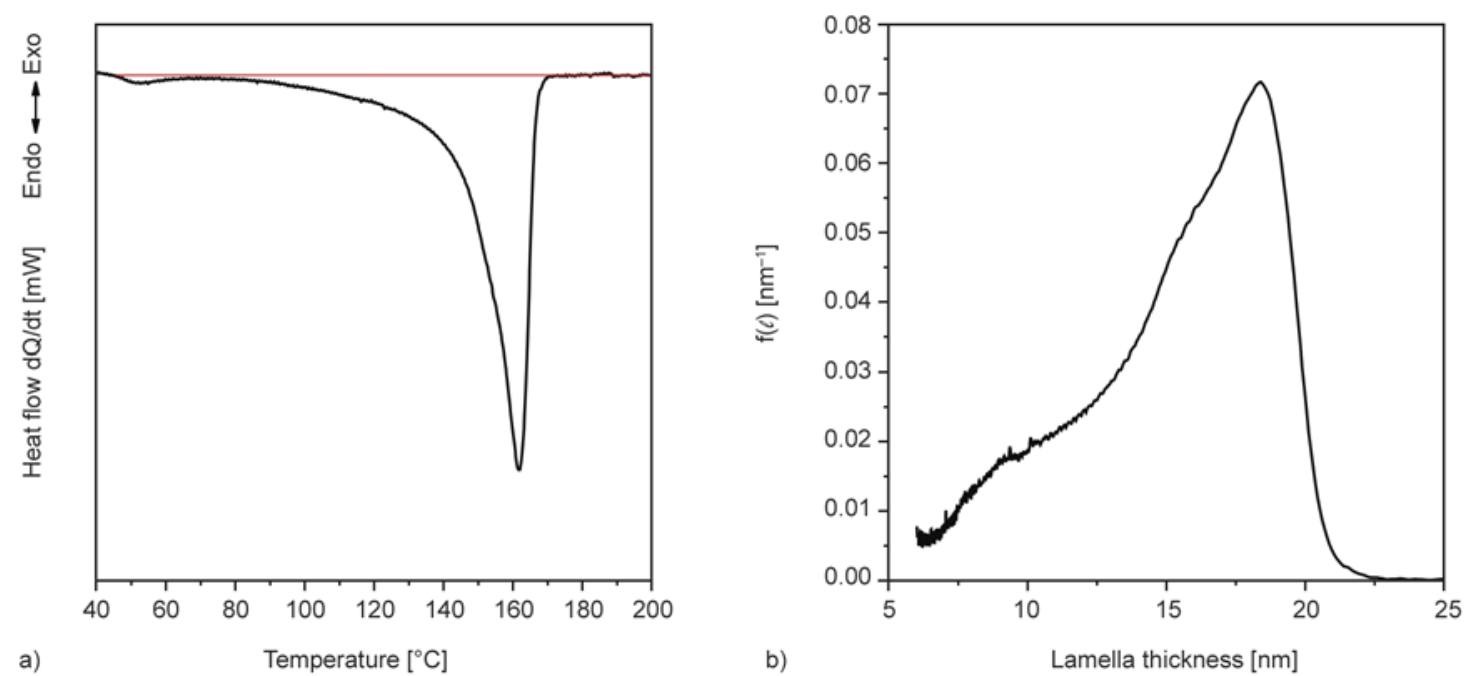

Figure 5. The melting curve recorded during first heating run of iPP1 (a) and the distribution function of lamella thickness (b) obtained according to Equation (7)
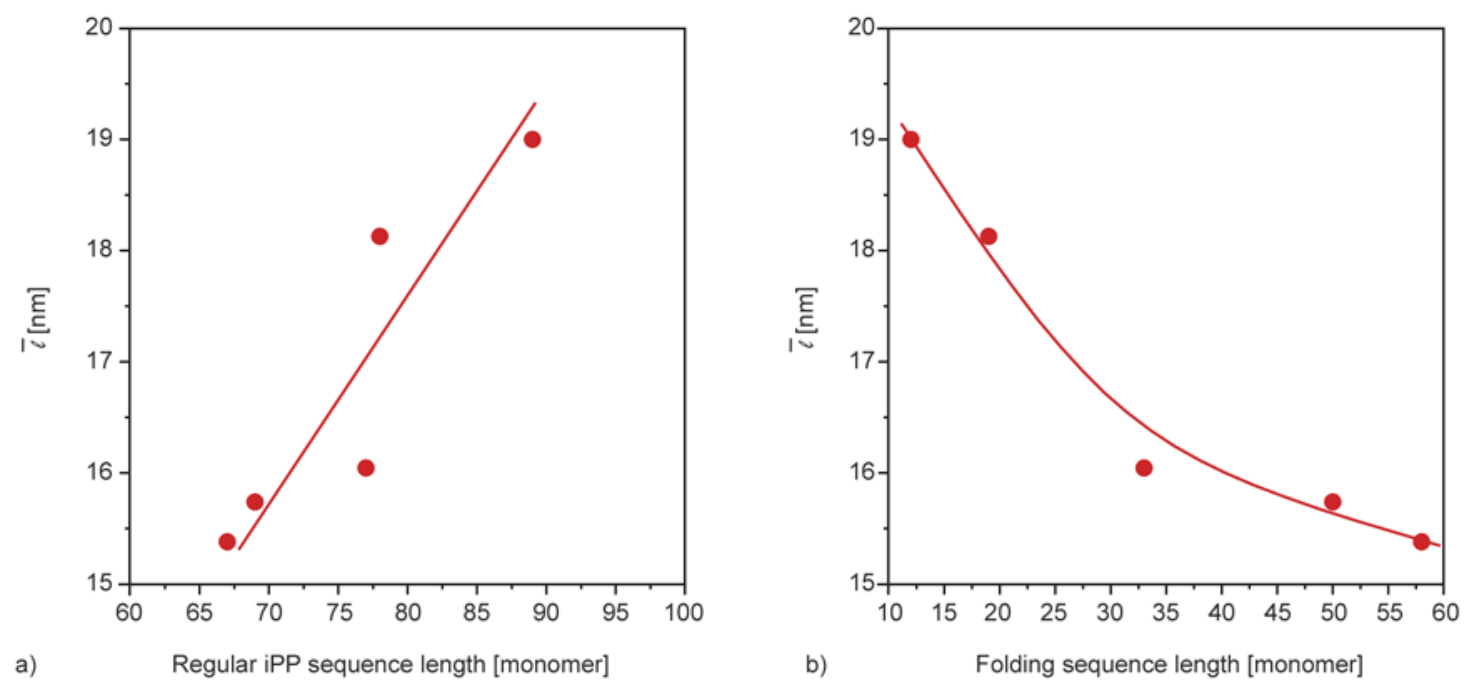

Figure 6. Relationship between $\bar{\ell}$ value and (a) regular iPP sequence or (b) folding length
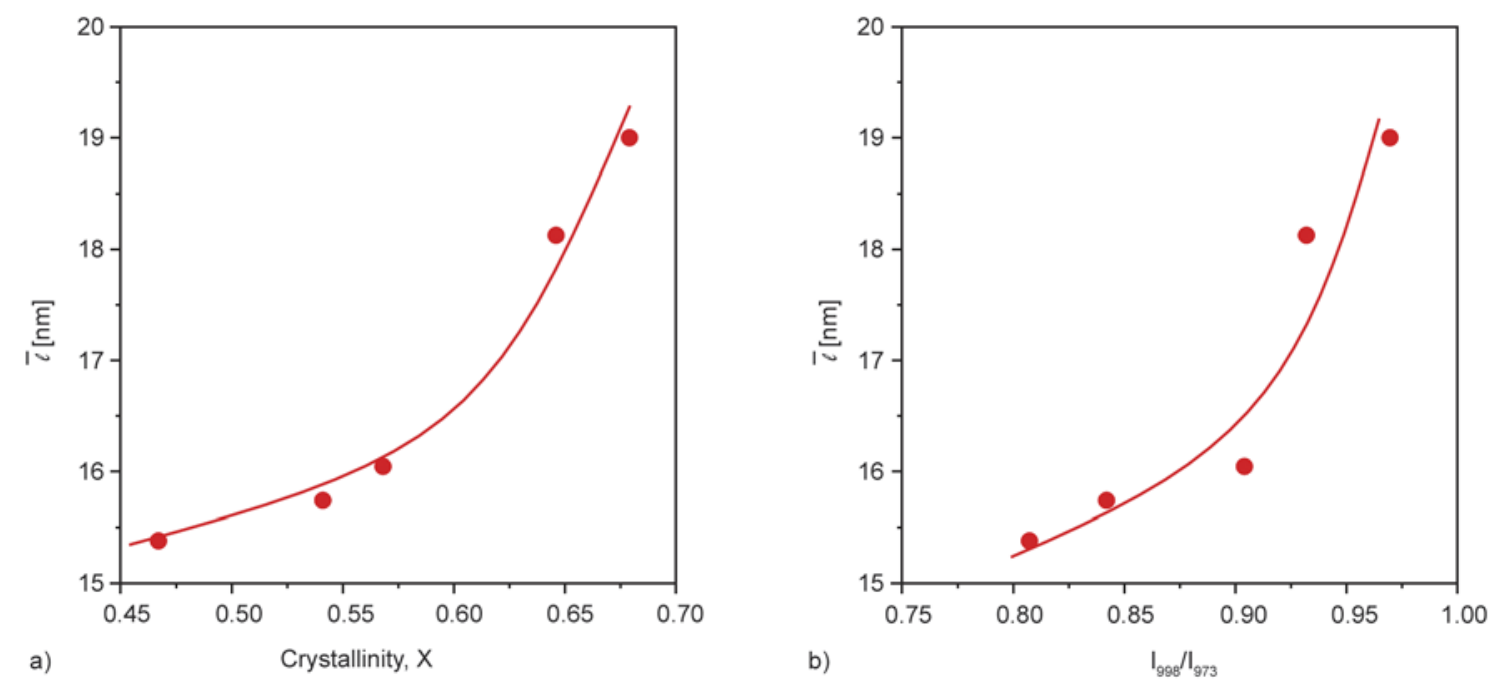

Figure 7. Correlation between $\bar{\ell}$ value and (a) crystallinity or (b) isotacticity 
$f(\ell)$ is the distribution function of lamella thickness and $\ell$ is the lamella thickness. The obtained $\bar{\ell}$ is the weight average of the distribution function and its value is plotted against the parameters of chain regularity in Figure 6 and 7.

It is well discernable that regular sequence length correlates strongly with lamella thickness. The longer the regular iPP chain, the thicker lamellas are formed in the polymer. The correlation seems to be close to linear in spite of the scattering of the points. $F$ correlates strongly with lamella thickness as well, but the relationship is not linear. The results indicate unambiguously that high chain regularity results in the formation of thick lamellas. In the case of lower regularity lamella thickness decrease considerably, but crystallinity can be still relatively large. This tendency is represented by the non-linear relationship between lamella thickness and $X$ (Figure 7).

\subsection{Tensile properties}

The results of tensile test are presented in Table 6 . Mechanical properties of the studied samples differ considerably because of their significantly different crystalline structure indicating that the conditions of polymerization determine the properties of the product. In addition the stress at yield values correlate strongly with the modulus values, proving that the tensile measurements are reliable. The modulus values and their correlation with stress at yield are represented in Figure 8.

Effect of chain regularity on modulus is given in Figure 9. As it was suspected the chain regularity determined by the SIST measurement correlates

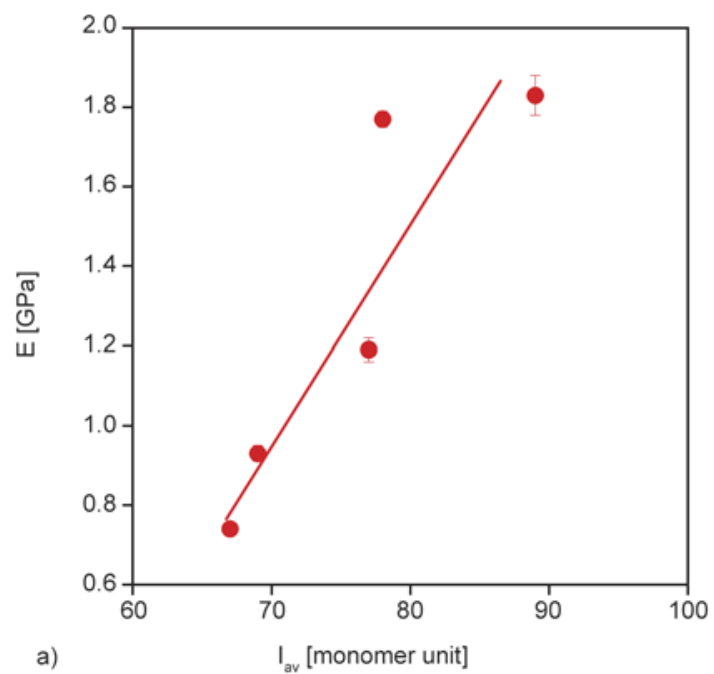

Figure 9. The effect of $I_{\mathrm{av}}(\mathrm{a})$ and $F(\mathrm{~b})$ on modulus
Table 6. The results of tensile tests

\begin{tabular}{|l|c|c|c|}
\hline \multicolumn{1}{|c|}{ Sample } & $\begin{array}{c}\boldsymbol{E} \\
{[\mathbf{G P a}]}\end{array}$ & $\begin{array}{c}\boldsymbol{\sigma}_{\mathbf{y}} \\
{[\mathbf{M P a}]}\end{array}$ & $\begin{array}{c}\boldsymbol{\varepsilon}_{\mathbf{y}} \\
{[\mathbf{\%}]}\end{array}$ \\
\hline iPP1 & $0.74 \pm 0.01$ & $20.30 \pm 0.24$ & $12.27 \pm 0.60$ \\
\hline iPP2 & $0.93 \pm 0.02$ & $24.15 \pm 0.40$ & $11.71 \pm 0.36$ \\
\hline iPP3 & $1.19 \pm 0.03$ & $28.11 \pm 0.19$ & $9.36 \pm 0.47$ \\
\hline iPP4 & $1.77 \pm 0.02$ & $36.92 \pm 0.36$ & $6.31 \pm 0.39$ \\
\hline iPP5 & $1.83 \pm 0.05$ & $35.16 \pm 0.83$ & $5.43 \pm 0.20$ \\
\hline
\end{tabular}

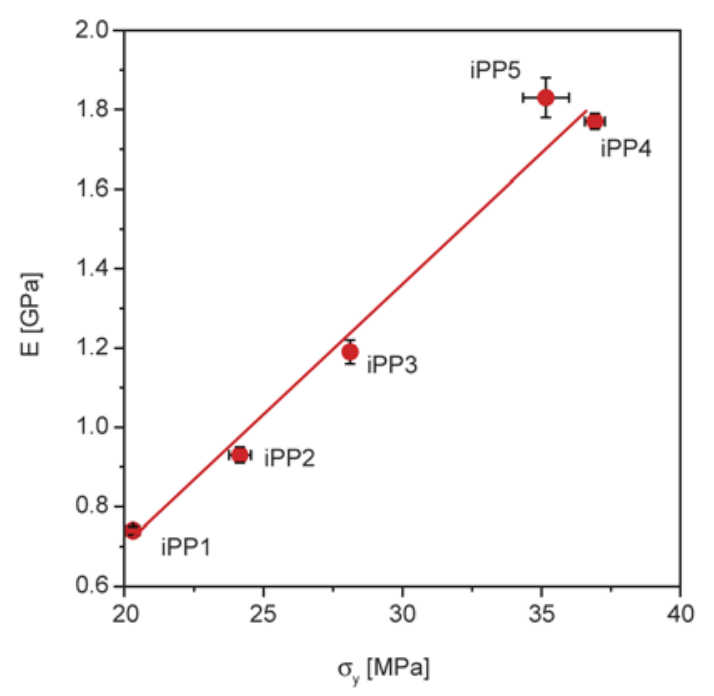

Figure 8. Modulus as a function of stress at yield values of studied samples

strongly with the modulus. The more regular chain structure is accompanied by proportionally larger modulus. Similar correlation can be found between the modulus and isotacticity as well. Since these molecular parameters are influencing the tendency for crystallization they affect the crystalline structure and consequently the modulus according to the same way (Figure 10).

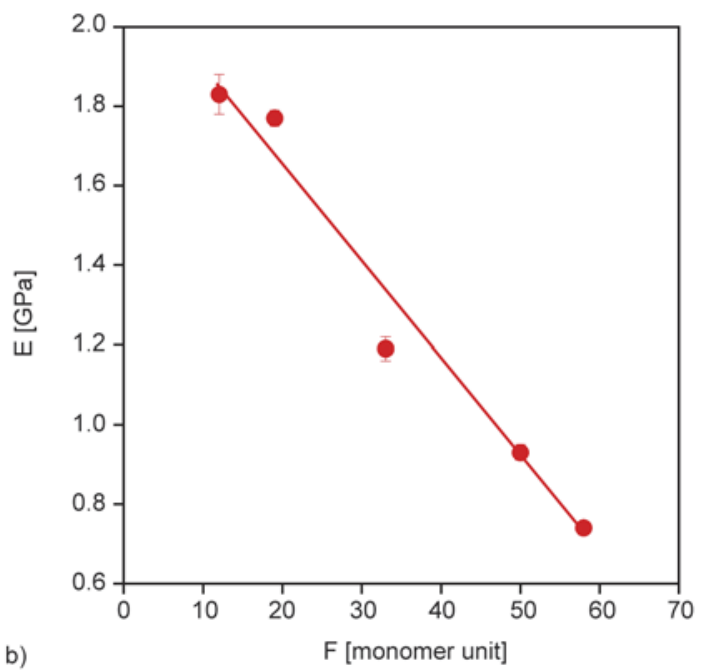




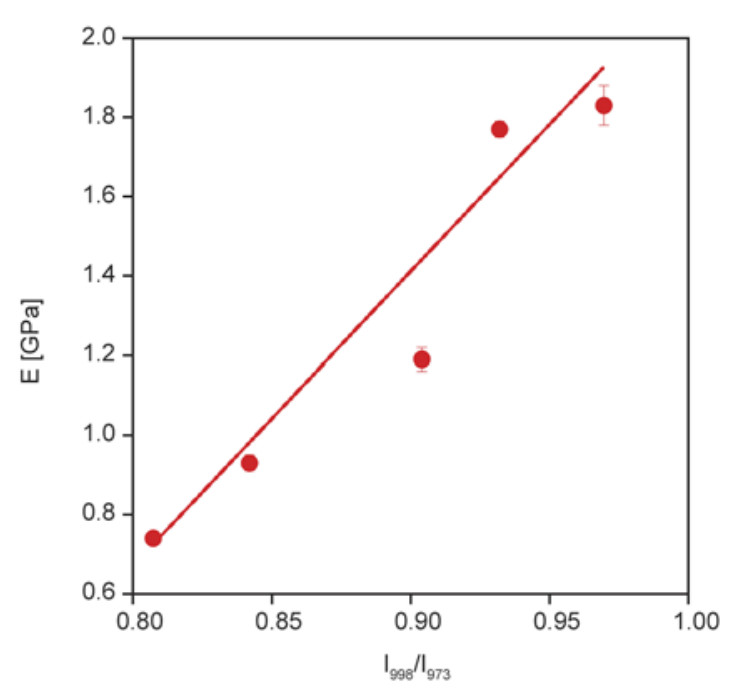

Figure 10. The modulus as a function of isotacticity

The modulus is plotted as a function of lamella thickness and crystallinity in Figure 11. It is clear that modulus depends strongly on both parameters, however the correlation seems not to be linear if the entire crystallinity range is demonstrated for example (Figure 11b). Although, a linear function can be fitted to the plots from $X \approx 0.5$ to 0.7 , which covers the range of iPP grades in the practice. That is why the linear correlation developed by Pukánszky and coworkers $[7,38]$ provides accurate results. The shape of the curve at lower lamella thickness and crystallinity can be speculated on (marked with dashed line in Figure 11), but the shape of the correlation at large lamella thickness and crystallinity is completely unknown. Therefore the modeling of stiffness in the upper region is an important question of material design and development, even if the modeling is based on empirical correlations.

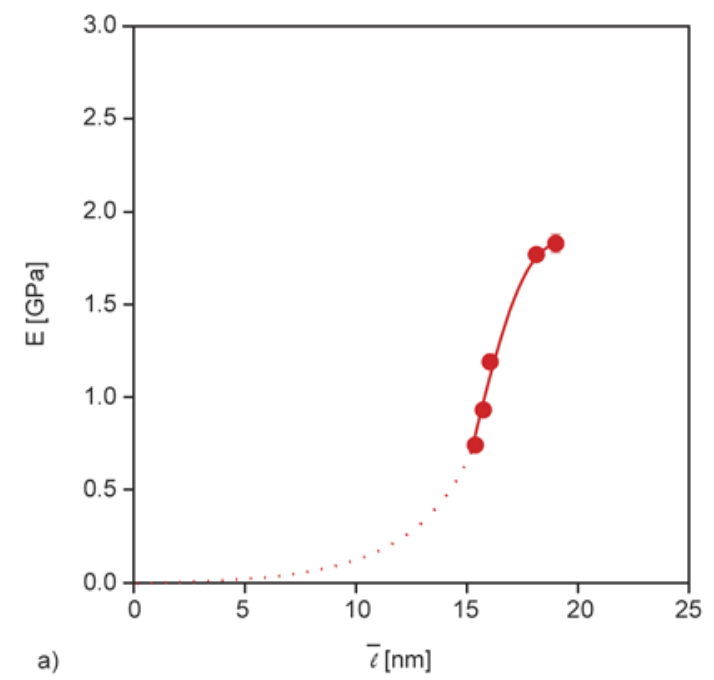

\subsection{Empirical modeling of stiffness using structural parameters}

Based on the earlier results $[7,38]$ and our experimental data it can be concluded that stiffness depends predominantly on crystallinity and lamella thickness. Consequently, the following expression should be solved (Equation (9)):

$E=f(X, \bar{\ell})$

$E$ is the elastic moduli of iPP, $X$ is the crystallinity and $\bar{\ell}$ is the weight average of lamella thickness function in Equation (9). We have to note that stiffness changes from a minimum to a maximum value. The minimum stiffness $\left(E_{\min }\right)$ is the stiffness of the amorphous iPP and it is in the range of 0.01$0.02 \mathrm{GPa}$ depending on the molecular mass [39]. $0.01 \mathrm{GPa}$ was used in our study as $E_{\min }$ value. The maximum stiffness $\left(E_{\max }\right)$ is the stiffness of the perfect iPP crystal, which value cannot be obtained experimentally. Moreover, it depends on the unit cell geometry of iPP, thus it should depend on the direction as well. $E_{\max }$ can be calculated only theoretically from the propagation of longitudinal sound waves in the material according to the suggestion of van Krevelen and Nijenhuis [40]. The propagation rate depends on the crystallinity and experimental data can be extrapolated linearly to a perfect crystal $(X=1$ in polymeric materials). The elastic modulus determines the vibration of the neighboring molecules, consequently the Equation (10) can be written:

$E=u_{\mathrm{L}}^{2} \rho_{\mathrm{cr}}$

where $E$ is the elastic modulus, $u_{\mathrm{L}}$ is the propagation rate of the sound wave. The extrapolated value of $u_{\mathrm{L}}$

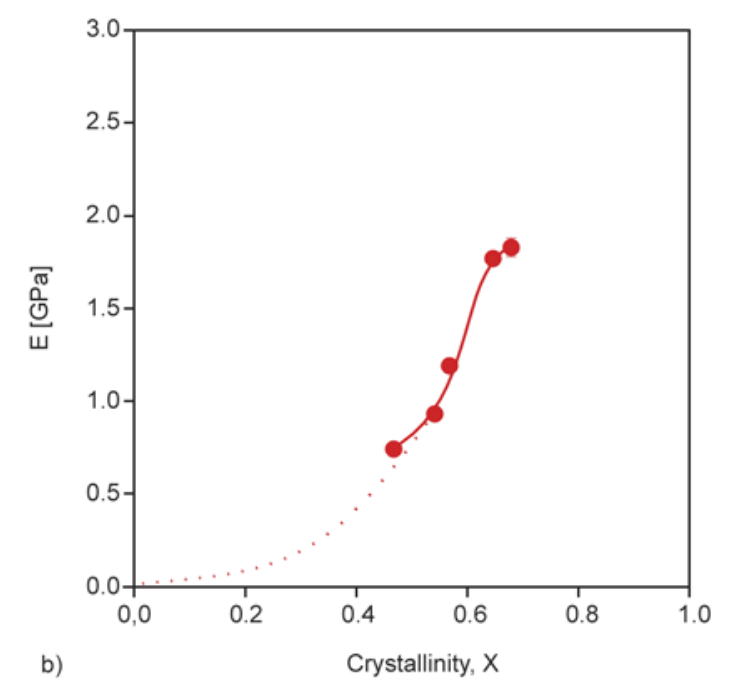

Figure 11. The modulus as a function of the two major parameters of crystalline structure - a) lamella thickness, b) crystallinity 
for iPP is $2650 \mathrm{~m} / \mathrm{s}$ [40] and the crystal density is $936 \mathrm{~kg} / \mathrm{m}^{3}$ (see in Table 2). Accordingly, the calculated $E_{\max }$ is $6.6 \mathrm{GPa}$ using the above data and Equation (10). We have to note that this value is much smaller that the theoretical stiffness along the polymer chain obtained by Kunugi [41] and Sawatari and Matuso [42] based on molecular dynamic calculations. The calculated $E_{\max }=6.6 \mathrm{GPa}$ is more realistic, since it is valid without any orientation in the sample. Considering the abovementioned $E_{\min }$ and $E_{\max }$ data, an empirical function is suggested to describe the stiffness in the entire crystallinity range (Equation (11)):

$E=E_{\text {min }}+\left(E_{\text {max }}-E_{\min }\right) \mathrm{e}^{\left(-\left(\frac{1-\mathrm{X}}{\mathrm{X}}\right)^{\alpha} \cdot\left(\frac{1}{\ell_{\mathrm{av}}}\right)^{\beta}\right)^{\gamma}}$

where $E$ is the modulus, $X$ is the crystallinity, $\ell_{\mathrm{av}}$ is the average lamella thickness and $\alpha, \beta, \gamma$ are iterative parameters characteristics for iPP. Equation (11) gives back $E_{\min }$ and $E_{\max }$ for completely amorphous $\left(X=0\right.$ and $\left.\ell_{\mathrm{av}}=0\right)$ and perfectly crystalline $(X=1$ and $\left.\ell_{\mathrm{av}}=\infty\right)$ iPP respectively. We have to point out that $X$ and $\ell_{\mathrm{av}}$ are handled as independent parameters in Equation (11), despite the fact that larger $X$ might be accompanied by proportionally thicker lamellas in iPP homopolymers (See in Figure 7a). The following formula is used to describe the correlation between $\ell_{\mathrm{av}}$ and $X$ presented in Figure $7 \mathrm{a}$ in the entire crystallinity range (Figure 12) (Equation (12)):

$\ell_{\mathrm{av}}=a+b \mathrm{e}^{\left(\frac{\mathrm{x}}{1-\mathrm{X}}\right)^{\mathrm{c}}}$

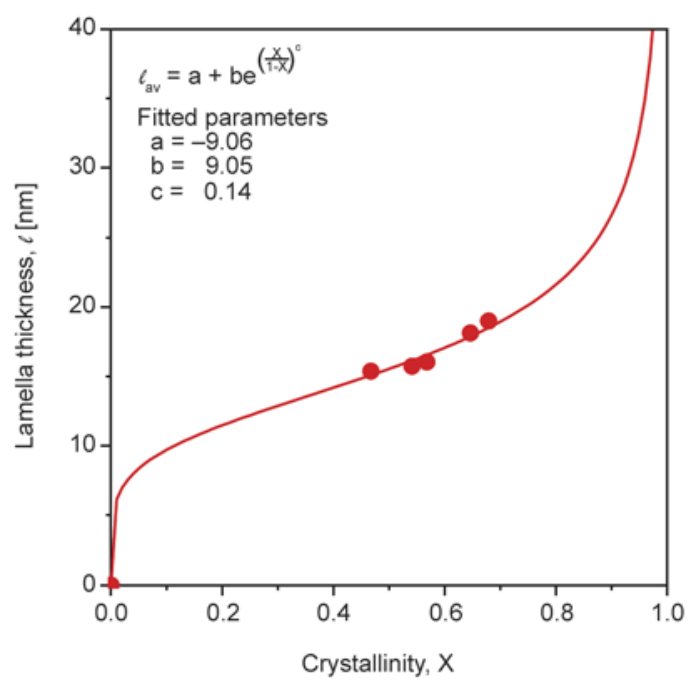

Figure 12. Fitting Equation (12) to lamella thickness crystallinity data
The correlation demonstrated in Figure 12 is in good agreement with our expectations, because lamella thickness is infinite at $X=1$ and decrease to zero at low crystallinity. Moreover, it demonstrates clearly that the lamella thickness increases steeply at low crystallinity, which means that the formation of thinner lamella than $5-8 \mathrm{~nm}$ is not probable even in the low crystallinity PP grades. Using Equation (3), we can recalculate that in average at least 20-30 regular monomer units are necessary to form crystalline structure. The variables of $a, b$ and $c$ are iterative parameters without any physical meaning, but using these values the number of independent variables in Equation (11) can be reduced to the crystallinity $(X)$ only and Equation (11) can be fitted to the experimental data shown in Figure 11b. The fitted curve can be seen in Figure 13.

Once the parameter set of $\alpha, \beta$ and $\gamma$ is determined the modulus of iPP samples can be predicted using Equation (11) in the entire crystallinity range if $X$ and $\ell_{\mathrm{av}}$ are available. Figure 14 represents the calculated and measured modulus values of several unpublished iPP samples studied earlier. Both random copolymers and homopolymers were included in this prediction in order to check the validity of the proposed empirical equation. The results indicate clearly that the prediction is accurate and reliable. Although, the results show some scattering, which may originate from experimental errors and inaccuracies, the predicted values are close to the measured ones consequently Equation (11) can be used for predicting of modulus form crystalline parameters obtained from calorimetric curves.

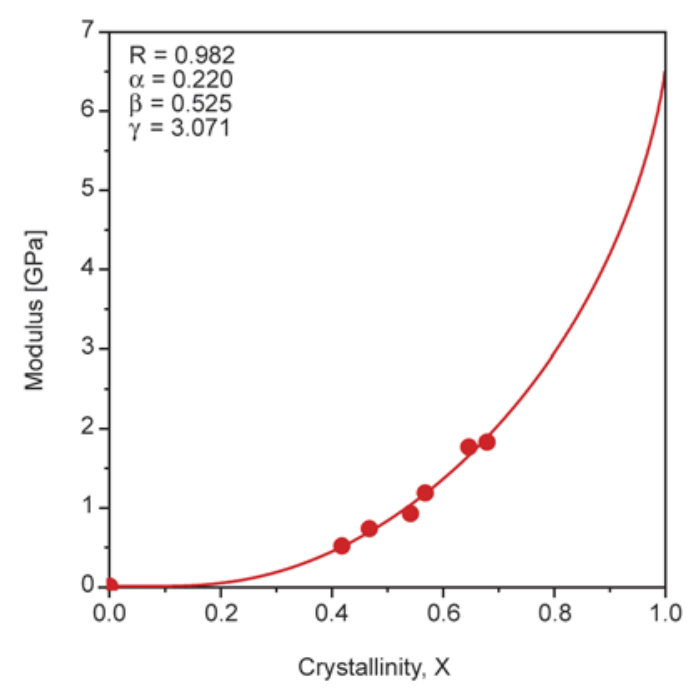

Figure 13. Fitting Equation (11) to modulus - crystallinity data 


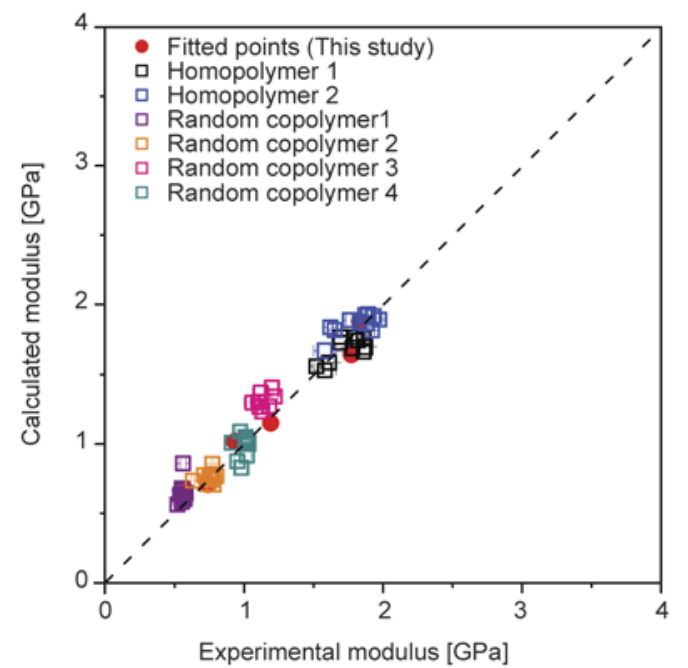

Figure 14. Correlation between the measured and calculated modulus values

\subsection{Prediction of structure with desired properties}

The improvement of stiffness is a crucial issue in the industrial practice. Polypropylene grades have stiffness in the range of $1.5-2.5 \mathrm{GPa}$, which is much smaller than the calculated 6.6 GPa. Recently, the desired limit value to be exceeded is $3 \mathrm{GPa}$. Using our simple equation the crystalline structure necessary to fulfill this need can be predicted, if we simulate the modulus using fixed crystallinity or lamella thickness data. Figure 15 presents such simulation. The data demonstrated in Figure 15 indicate clearly that $3 \mathrm{GPa}$ is reachable. Figure $15 \mathrm{a}$ presents that lamella thickening has a limited effect. Only the lamella thickness below $30 \mathrm{~nm}$ influences stiffness. Although, it is also clearly demonstrated in this Fig-

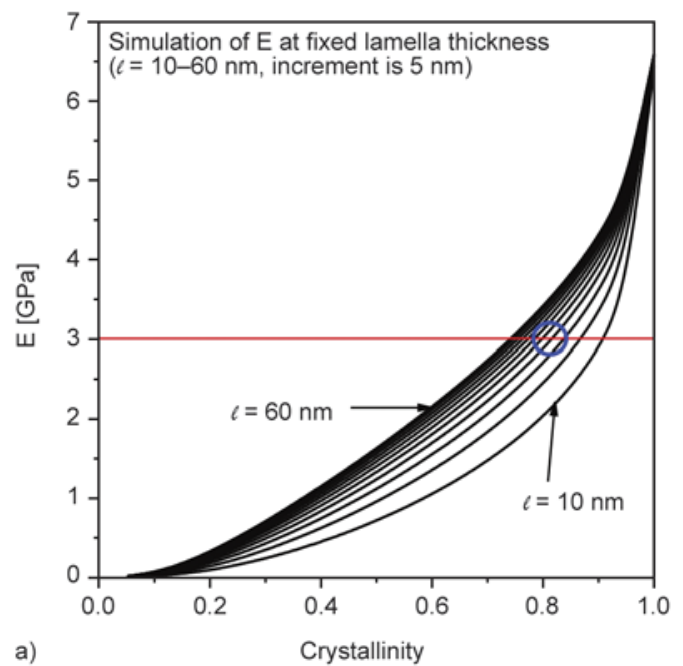

ure, that thicker lamellas result in larger modulus at the same level of crystallinity. The effect of improvement in crystallinity can be seen in Figure $15 \mathrm{~b}$ and it is well discernible that the $3 \mathrm{GPa}$ cannot be exceeded if crystallinity is smaller than $70 \%$. These simulated results indicate that the desired mechanical properties can be achieved if crystallinity is around $75 \%$ and lamella thickness is larger than $30 \mathrm{~nm}$. This is in good agreement with our earlier results that $3 \mathrm{GPa}$ of modulus can be reached by carefully designed annealing experiments [38].

\section{Conclusions}

iPP grades with significantly different chain regularities were studied in order to describe the effect of molecular architecture on the crystalline structure and consequently the influence on stiffness. The results support clearly the well-known fact that the increased chain regularity results in larger crystallinity and the formation of thicker lamellas and consequently proportionally larger modulus. Moreover, the deep analysis of chain structure revealed that crystallinity and lamella thickness are two independent parameters of crystalline structure despite of the fact that they show correlation in several cases. The results proved clearly that the modulus of the iPP products depends strongly on the crystallinity and lamella thickness, which correlation was characterized quantitatively. The upper lower boundary of modulus was determined and an empirical correlation was developed, which links the modulus to the crystalline structure. A parameter set was obtained for iPP and using the suggested empirical equation and these parameters, the modulus of

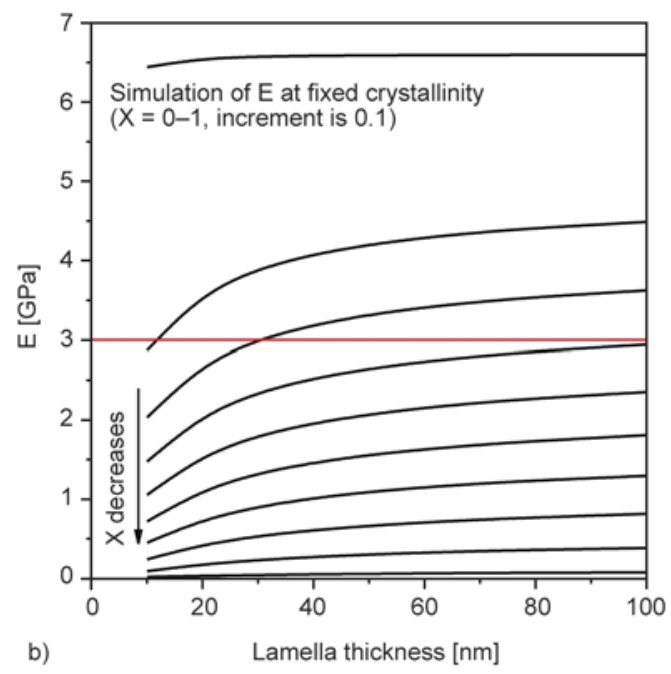

Figure 15. Modulus values predicted using (a) fixed lamella thickness or (b) fixed crystallinity values 
injection molded iPP samples can be calculated from the crystallinity and lamella thickness data obtained from calorimetric experiments. A crystalline structure was predicted using the equation given this work for exceeding $3 \mathrm{GPa}$ of elastic modulus without any reinforcement. Lamella thickness and crystallinity should be larger than $30 \mathrm{~nm}$ and $75 \%$ according to the prediction. We have to note that both parameters are influenced by chain regularity, which has to be increased significantly in order to fulfill this goal.

\section{Acknowledgements}

The Authors would like to express their gratitude to the János Bolyai Research Scholarship of the Hungarian Academy of Sciences and for the financial support of the National Scientific Research Fund of Hungary (OTKA Grant PD 109346) for the project on the structure-property correlations of polymeric materials.

\section{References}

[1] Moore E. P.: Polypropylene handbook: Polymerization, characterization, properties, processing, applications. Hanser-Gardner Publications, Cincinnati (1996).

[2] Varga J.: Crystallization, melting and supermolecular structure of isotactic polypropylene. in 'Polypropylene: Structure, blends and composites' (ed.: Karger-Kocsis J.) Chapmann and Hall, London, Vol 1, 56-115 (1995).

[3] Varga J.: Supermolecular structure of isotactic polypropylene. Journal of Materials Science, 27, $2557-$ 2579 (1992).

DOI: $10.1007 / \mathrm{BF} 00540671$

[4] Padden F. J., Keith H. D.: Spherulitic crystallization in polypropylene. Journal of Applied Physics, 30, 14791484 (1959).

DOI: $10.1063 / 1.1734985$

[5] Lotz B., Wittmann J. J., Lovinger A. J.: Structure and morphology of poly(propylenes): A molecular analysis. Polymer, 37, 4979-4992 (1996). DOI: 10.1016/0032-3861(96)00370-9

[6] Phillips P., J., Mezghani K.: Polypropylene, isotactic (polymorphism). in 'The polymeric materials encyclopedya’ (ed.: Salamone J. C.) CRC Press, Boca Raton, Vol 9, 6637-6649 (1996).

[7] Pukánszky B., Mudra I., Staniek P.: Relation of crystalline structure and mechanical properties of nucleated polypropylene. Journal of Vinyl and Additive Technology, 3, 53-57 (1997).

DOI: $10.1002 /$ vnl.10165

[8] Alberola N., Fugier M., Petit D., Fillon B.: Tensile mechanical behaviour of quenched and annealed isotactic polypropylene films over a wide range of strain rates. Journal of Materials Science, 30, 860-868 (1995). DOI: $\underline{10.1007 / \mathrm{BF} 01178418}$
[9] Kalay G., Bevis M. J.: Processing and physical property relationships in injection-molded isotactic polypropylene. 1. Mechanical properties. Journal of Polymer Science Part B: Polymer Physics, 35, 241263 (1997).

DOI: 10.1002/(SICI)1099-0488(19970130)35:2<241:: AID-POLB5>3.0.CO;2-V

[10] Fujiyama M.: Higher order structure of injectionmolded polypropylene. in 'Polypropylene: Structure, blends and composites' (ed.: Karger-Kocsis J.) Chapmann and Hall, London, Vol 1, 167-204 (1995).

[11] Mitsuishi K.: Polypropylene, nucleating agents. in 'The polymeric materials encyclopedya' (ed.: Salamone J. C.) CRC Press, Boca Raton, Vol 9, 6602-6609 (1996).

[12] Binsbergen F. L.: Heterogeneous nucleation in the crystallization of polyolefins: Part 1. Chemical and physical nature of nucleating agents. Polymer, 11, 253-267 (1970).

DOI: $10.1016 / 0032-3861(70) 90036-4$

[13] Wunderlich B.: Crystal nucleation, growth, annealing. Academic Press, London (1979).

[14] Bassett D. C.: Polymer morphology: A guide to macromolecular self-organization. Macromolecular Symposia, 214, 5-16 (2004).

DOI: $10.1002 /$ masy.200451002

[15] Avella M., dell'Erba R., Martuscelli E., Ragosta G.: Influence of molecular mass, thermal treatment and nucleating agent on structure and fracture toughness of isotactic polypropylene. Polymer, 34, 2951-2960 (1993).

DOI: 10.1016/0032-3861(93)90620-P

[16] Varga J.: $\beta$-modification of isotactic polypropylene: preparation, structure, processing, properties, and application. Journal of Macromolecular Science Part B: Physics, 41, 1121-1171 (2002).

DOI: 10.1081/MB-120013089

[17] Menyhárd A., Varga J., Molnár G.: Comparison of different -nucleators for isotactic polypropylene, characterisation by DSC and temperature-modulated DSC (TMDSC) measurements. Journal of Thermal Analysis and Calorimetry, 83, 625-630 (2006).

DOI: $10.1007 / \mathrm{s} 10973-005-7498-6$

[18] Mai J. H., Zhang M. Q., Rong M. Z., Bárány T., Ruan W. H.: Crystallization behavior and mechanical properties of nano- $\mathrm{CaCO}_{3} / \beta$-nucleated ethylene-propylene random copolymer composites. Express Polymer Letters, 6, 739-749 (2012).

DOI: 10.3144 /expresspolymlett.2012.79

[19] Stern C., Frick A., Weickert G.: Relationship between the structure and mechanical properties of polypropylene: effects of the molecular weight and shear-induced structure. Journal of Applied Polymer Science, 103, 519-533 (2007).

DOI: $10.1002 / a p p .24156$ 
[20] Gahleitner M., Berneitner K., Neiß1 W., Paulik C., Ratajski E.: Influence of molecular structure on crystallization behaviour and mechanical properties of polypropylene. Polymer Testing, 14, 173-187 (1995). DOI: 10.1016/0142-9418(95)93196-8

[21] Halpin J. C., Kardos J. L.: Moduli of crystalline polymers employing composite theory. Journal of Applied Physics, 43, 2235-2241 (1972).

DOI: $10.1063 / 1.1661482$

[22] McCullough R. L., Wu C. T., Seferis J. C., Lindenmeyer P. H.: Predictions of limiting mechanical performance for anisotropic crystalline polymers. Polymer Engineering and Science, 16, 371-387 (1976).

DOI: $10.1002 /$ pen.760160517

[23] Boyd R. H.: Prediction of polymer crystal structures and properties. Atomistic Modeling of Physical Properties, 116, 1-25 (1994).

DOI: $10.1007 / \mathrm{BFb} 0080195$

[24] Boyd R. H.: The mechanical moduli of lamellar semicrystalline polymers. Journal of Polymer Science: Polymer Physics Edition, 21, 493-504 (1983).

DOI: $10.1002 /$ pol.1983.180210401

[25] Crist B., Fisher C. J., Howard P. R.: Mechanical properties of model polyethylenes: Tensile elastic modulus and yield stress. Macromolecules, 22, 1709-1718 (1989).

DOI: $10.1021 / \mathrm{ma} 00194 \mathrm{a} 035$

[26] Doyle M. J.: On the effect of crystallinity on the elastic properties of semicrystalline polyethylene. Polymer Engineering and Science, 40, 330-335 (2000).

DOI: $10.1002 /$ pen.11166

[27] Fatahi S., Ajji A., Lafleur P. G.: Correlation between different microstructural parameters and tensile modulus of various polyethylene blown films. Polymer Engineering and Science, 47, 1430-1440 (2007).

DOI: $10.1002 /$ pen.20836

[28] Monasse B., Haudin J. M.: Growth transition and morphology change in polypropylene. Colloid and Polymer Science, 263, 822-831 (1985).

DOI: $10.1007 / \mathrm{BF} 01412960$

[29] Varga J., Menczel J., Solti A.: The melting of highpressure polyethylene subjected to stepwise heat treatment. Journal of Thermal Analysis, 17, 333-342 (1979). DOI: $10.1007 / \mathrm{BF} 01914024$

[30] Varga J., Menczel J., Solti A.: Memory effect of lowdensity polyethylene crystallized in a stepwise manner. Journal of Thermal Analysis, 10, 433-440 (1976). DOI: $10.1007 / \mathrm{BF} 01909895$

[31] Garoff T., Virkkunen V., Jääskeläinen P., Vestberg T.: A qualitative model for polymerisation of propylene with a $\mathrm{MgCl}_{2}$-supported $\mathrm{TiCl}_{4}$ Ziegler-Natta catalyst. European Polymer Journal, 39, 1679-1685 (2003). DOI: $10.1016 / \mathrm{S} 0014-3057(03) 00069-7$
[32] Horváth Zs., Menyhárd A., Doshev P., Gahleitner M., Varga J., Tranninger C., Pukánszky B.: Chain regularity of isotactic polypropylene determined by different thermal fractionation methods. Journal of Thermal Analysis and Calorimetry, 118, 235-245 (2014). DOI: 10.1007/s10973-014-3999-5

[33] Bai F., Li F., Calhoun B. H., Quirk R. P., Cheng S. Z. D.: Physical constants of poly(propylene). in 'Polymer handbook' (eds.: Brandrup J., Immergut E. H., Grulke E. A.) Wiley, New Jersey, Vol 1, V/21-30 (1999).

[34] Clark E. J., Hoffman J. D.: Regime III crystallization in polypropylene. Macromolecules, 17, 878-885 (1984). DOI: $10.1021 / \mathrm{ma} 00134 \mathrm{a} 058$

[35] Boger A., Heise B., Troll C., Marti O., Rieger B.: Mechanical and temperature dependant properties, structure and phase transitions of elastic polypropylenes. European Polymer Journal, 43, 634-643 (2007). DOI: $10.1016 /$ j.eurpolymj.2006.11.003

[36] Sundell T., Fagerholm H., Crozier H.: Isotacticity determination of polypropylene using FT-Raman spectroscopy. Polymer, 37, 3227-3231 (1996). DOI: 10.1016/0032-3861(96)88466-7

[37] Romankiewicz A., Sterzynski T.: The lamellar distribution in isotactic polypropylene modified by nucleation and processing. Macromolecular Symposia, 180, 241-256 (2002).

DOI: $10.1002 / 1521-3900(200203) 180: 1<241:: A I D-$ MASY241>3.0.CO;2-9

[38] Horváth Zs., Menyhárd A., Doshev P., Gahleitner M., Tranninger C., Kheirandish S., Varga J., Pukánszky B.: Effect of molecular architecture on the crystalline structure and stiffness of iPP homopolymers: Modeling based on annealing experiments. Journal of Applied Polymer Science, 130, 3365-3373 (2013). DOI: $10.1002 /$ app.39585

[39] Mouzakis D. E., Gahleitner M., Karger-Kocsis J.: Toughness assessment of elastomeric polypropylene (ELPP) by the essential work of the fracture method. Journal of Applied Polymer Science, 70, 873-881 (1998).

DOI: $10.1002 /($ sici) 1097-4628(19981031)70:5<873:: aid-app6 $>3.0 . c 0 ; 2-q$

[40] van Krevelen D. V., Nijenhuis K. T.: Properties of polymers. Elsevier, Amsterdam (2009).

[41] Kunugi T.: High-modulus and high-strength polypropylene fibres and films. in 'Polypropylene A-Z reference' (ed.: Karger-Kocsis J.) Kluwer, Dordrecht, 295-300 (1999).

[42] Sawatari C., Matsuo M.: Elastic modulus of isotactic polypropylene in the crystal chain direction as measured by X-ray diffraction. Macromolecules, 19, 26532656 (1986). DOI: $10.1021 / \mathrm{ma} 00164 \mathrm{a} 036$ 